\title{
Moderate Alcohol Consumption and Triglyceridemia
}

\author{
J. KOVÁŘ ${ }^{1}$, K. ZEMÁNKOVÁ ${ }^{1}$ \\ ${ }^{1}$ Laboratory for Atherosclerosis Research, Centre for Experimental Medicine, Institute for Clinical \\ and Experimental Medicine, Prague, Czech Republic
}

Received September 3, 2015

Accepted September 17, 2015

\begin{abstract}
Summary
The review aims to summarize current knowledge on the effects of moderate alcohol consumption ( 1 standard drink a day for women; 2 drinks a day for men) on triglyceride concentration in circulation. Current evidence suggests that the relationship between alcohol consumption and triglyceridemia is J-shaped. Triglyceridemia is lowest in subjects who drink 10-20 g/alcohol a day. Such a J-shaped association is comparable with that described for the relationship between alcohol and cardiovascular risk. On the contrary, alcohol taken with a meal increases and prolongs postprandial triglyceridemia. Such effects of alcohol consumption may be at least partially explained by the effects of ethanol on lipoprotein lipase (LPL) activity. Long-term moderate alcohol consumption increases LPL activity, which may explain its TG-lowering effect. On the other hand, LPL activity is acutely downregulated by ethanol, which explains increased postprandial triglyceridemia.
\end{abstract}

\section{Key words}

Alcohol consumption • Triglyceride • Lipoprotein lipase • Ethanol

\section{Corresponding author}

J. Kovár, Institute for Clinical and Experimental Medicine, Laboratory for Atherosclerosis Research, Vídeňská 1958/9, 14021 Prague 4, Czech Republic. E-mail: jan.kovar@ikem.cz

\section{Introduction}

Over the last few decades, compelling evidence has accumulated regarding the protective effect of moderate alcohol consumption on cardiovascular disease morbidity and mortality (Corrao et al. 2000, Costanzo et al. 2010, Ronksley et al. 2011, Wang et al. 2014).
Although the definition of a moderate dose somewhat differs among authors, one drink a day (10-15 g of alcohol) for women and 2 drinks a day (20-30 g of alcohol) for men may be generally considered a moderate level of ethanol consumption. The relationship between alcohol consumption and cardiovascular morbidity and mortality is J-shaped - Corrao et al. (2000) have shown that the protective effect of alcohol consumption reaches its maximal level at $20 \mathrm{~g}$ of alcohol/day and is preserved up to $72 \mathrm{~g} /$ day. The protective dosage of alcohol is lower in women compared to men (Corrao et al. 2000, Wang et al. 2014) and the protective effect of alcohol can even be seen in hypertensive patients (Wang et al. 2014). Importantly, the same protective effect of alcohol consumption is observed for wine, beer (Costanzo et al. 2011) and even for spirits (Rimm et al. 1996) as a source of ethanol. The authors of a recent meta-analysis (Ronksley et al. 2011) even conclude that alcohol taken in moderation may have overall health benefits that outweigh the risks in selected groups of patients. In their opinion, the evidence (especially for ischemic heart disease) is strong enough and so further observational studies may only have limited value. They also suggest that it is time to debate how to integrate the available evidence into clinical practice. Although the conclusions about the protective role of ethanol consumption were challenged by a recent Mendelian randomisation study (Holmes et al. 2014), even this study confirms the protective effect of alcohol consumption in drinkers compared to abstainers.

The positive effects of moderate alcohol consumption on cardiovascular disease outcomes might be mediated by the favorable effects on some cardiovascular disease risk factors. A meta-analysis of 63 intervention 
studies documented that alcohol consumption favorably affects plasma HDL-cholesterol, apolipoprotein A-I, fibrinogen and adiponectin concentrations (Brien et al. 2011). Alcohol also decreases fasting insulin and glycated hemoglobin concentrations and, in women, improves insulin sensitivity (Schrieks et al. 2015).

On the other hand, alcohol consumption is recognized as a major cause of secondary hypertriglyceridemia (Baraona and Lieber 1979) and hypertriglyceridemia is currently accepted as a cardiovascular disease risk factor (Hokanson and Austin 1996, Sarwar et al. 2010, Jorgensen et al. 2013). However, the findings on the relationship between alcohol consumption in moderation and triglyceridemia are unequivocal and sometimes even confusing. The present review therefore aims to summarize the current knowledge of the effects of alcohol consumption in moderation on triglyceridemia in both fasting and postprandial states.

\section{Metabolism of alcohol}

Alcohol is carried to the liver, where it is enzymatically oxidized. The rate of alcohol elimination is influenced by factors such as diet, age, smoking, time of day, chronic alcohol consumption as well as genetics. Ethanol is metabolized in the liver by alcohol dehydrogenase (ADH) to form acetaldehyde. Consequently, acetaldehyde is rapidly oxidized to acetate by aldehyde dehydrogenase (ALDH2). The majority of the acetate resulting from alcohol metabolism escapes from the liver into the blood and is eventually metabolized to acetyl CoA, after which it is oxidized to $\mathrm{CO}_{2}$ in the heart, skeletal muscle and brain cells (Zakhari 2006). This spares carbohydrates and lipids from oxidation, and they may be used for lipogenesis in the liver (Siler et al. 1999). However, the impact on lipogenesis and VLDL secretion does not seem to be quantitatively important when alcohol is consumed in modest doses (Siler et al. 1998b, 1999). Furthermore, the oxidation of alcohol to acetate results in an increase of $\mathrm{NADH} / \mathrm{NAD}^{+}$ratio in hepatocytes which inhibits gluconeogenesis, $\beta$-oxidation and the tricarboxylic acid cycle (Krebs et al. 1969, Siler et al. 1998a).

\section{Alcohol consumption and fasting triglyceri- demia}

The interpretation of the results of studies on the relationship between alcohol consumption and $\mathrm{TG}$ concentration is complicated by the fact that these data come from uncontrolled observational studies. Since the data on alcohol consumption are obtained from questionnaires, the validation of these data is very intricate. Moreover, there can be many different confounders of alcohol consumption, the pattern of alcohol consumption can differ between sexes and countries, while lifestyle and physical activity can also have an effect. This could serve as an explanation for the inconsistency of the results of studies that analyze the impact of ethanol consumption on triglyceridemia. However, a recent study of 8396 participants (Whitfield et al. 2013) supplied evidence for a J-shaped relationship between alcohol consumption and triglyceridemia - triglycerides were lowest in people reporting between three and twenty drinks per week (or 4 to $30 \mathrm{~g}$ of alcohol per day) (Whitfield et al. 2013). These findings are in agreement with work carried out on 9584 subjects from the Copenhagen City Heart Study (Tolstrup et al. 2009). They also observed a J-shaped association between alcohol intake and non-fasting triglycerides in women $(p=0.006)$, but not in men $(p=0.23)$. Accordingly, moderate alcohol consumption has even been associated with lower triglyceridemia according to a recent Mendelian randomization study (Lawlor et al. 2013). Therefore, there is growing evidence that low-to-moderate alcohol consumption is associated with a reduction of plasma triglycerides. The consumption of $20 \mathrm{~g}$ or less of alcohol per day can have a positive effect on TG concentration.

Important information can also be obtained from short-term intervention studies. The first metaanalysis of such studies (Rimm et al. 1999) concluded that alcohol consumption increases triglyceridemia ( $0.06 \mathrm{mmol} / 1$ per $30 \mathrm{~g}$ of alcohol consumed a day). However, a recent meta-analysis of 63 studies (Brien et al. 2011) did not confirm these findings and did not find any significant impact of alcohol consumption on TG concentration. If the relationship between alcohol consumption and triglyceridemia is indeed J-shaped, then an increase in alcohol intake might have no effect in subjects who drink very little, which could in turn explain why there is no overall effect of alcohol consumption. This could also provide an explanation for the discrepancies between the studies.

\section{Alcohol consumption and postprandial lipemia}

Torres do Rego et al. (2013) studied the effect of the daily amount of alcohol on diurnal triglyceridemia 
in 139 men. They showed that capillary triglyceridemia is lower in those who drink less than $10 \mathrm{~g}$ ethanol/day compared to abstainers and highest in those who drink more than $30 \mathrm{~g}$ ethanol/day. This may correspond with the idea that the relationship between TG concentration and the amount of alcohol consumed is J-shaped (Torres do Rego et al. 2013). On the other hand, studies on the effect of alcohol taken with a meal on postprandial lipemia consistently demonstrate markedly increased and even prolonged hypertriglyceridemia in the postprandial state (Pownall 1994, Chung et al. 2003, Mudrakova et al. 2013). However, the dose of alcohol used in these studies is in a range that is comparable to a high level in the above-mentioned study.

\section{Alcohol consumption and lipoprotein lipase}

Lipoprotein lipase (LPL) - a key enzyme in lipoprotein metabolism responsible for hydrolysis of TG in triglyceride-rich lipoproteins - is a rate-limiting factor of plasma triglyceride clearance (Kersten 2014). Consumption of alcohol in an amount considered moderate has been repeatedly shown to increase LPL activity in intervention studies when measured in the fasting state (Schneider et al. 1985, Nishiwaki et al. 1994, Kovar and Poledne 2004). Increased LPL activity could explain the decrease in $\mathrm{TG}$ concentration in subjects who consume a low amount of alcohol per day. On the contrary, LPL activity is acutely inhibited after alcohol consumption. This finding was previously documented by Nikkila et al. (1978) and Schneider et al. (1985) who measured LPL activity in post-heparin plasma after alcohol consumption. We confirmed these findings even in vivo using a repeated intravenous fat tolerance test to estimate LPL activity (Zemánková et al. 2015). The acute inhibition of LPL activity could contribute to the increased magnitude of postprandial lipemia when alcohol is taken together with a meal. The differences between the long-term response of LPL activity to alcohol and the acute inhibition of enzyme activity may explain the observed J-shaped relationship.

\section{Alcohol consumption and lipolysis in adipose tissue}

As far back as the 1960s, Crouse and colleagues showed that some metabolic effects of ethanol are mediated by acetate (Crouse et al. 1968). Recently, it has been shown that acetate signaling through G-proteincoupled receptor 43 (GPCR43) in adipose tissue results in the suppression of lipolysis and increased insulin sensitivity (Ge et al. 2008). Decreased lipolysis should result in the lower availability of free fatty acids for TG synthesis and for VLDL production in the liver, which may explain the observed effect of alcohol consumption on triglyceridemia. The administration of vinegar as a healthful alternative to alcohol consumption has even been recommended in a recent review (Pownall et al. 2015).

\section{Conclusion}

In summary, evidence that the relationship between alcohol consumption and triglyceridemia is J-shaped has gathered recently; alcohol consumed in a low dose can even decrease triglyceridemia compared to abstainers. It remains to be determined whether this J-shaped association between triglyceridemia and alcohol consumption can explain the described J-shaped curve for alcohol and cardiovascular risk. The effects of alcohol on TG concentration can be at least partially explained by the combination of long-term and acute effects of ethanol consumption on LPL activity.

The recommendation of moderate alcohol consumption in the prevention of cardiovascular disease remains a controversial area in preventive medicine. Due to the risk associated with the development of addiction to alcohol, it does not seem wise to recommend abstainers to start drinking alcohol. With regard to triglyceridemia as an independent factor of cardiovascular disease, the most appropriate recommendation for the Czech population (who in 2012 consumed on average $21.4 \mathrm{~g}$ of ethanol per capita per day, including newborns (Ritschelová 2014)) should be to reduce alcohol intake.

\section{Conflict of Interest}

There is no conflict of interest.

\section{Acknowledgements}

Supported by grant no. NT 14027-3/2013 from IGA MH CR. The Centre for Experimental Medicine (IKEM) received financial support from the European Commission within the Operational Programme, Prague - Competitiveness; project "CEVKOON" (\#CZ.2.16/3.1.00/22126). 


\section{References}

BARAONA E, LIEBER CS: Effects of ethanol on lipid metabolism. J Lipid Res 20: 289-315, 1979.

BRIEN SE, RONKSLEY PE, TURNER BJ, MUKAMAL KJ, GHALI WA: Effect of alcohol consumption on biological markers associated with risk of coronary heart disease: systematic review and meta-analysis of interventional studies. BMJ 342: d636, 2011.

CHUNG BH, DORAN S, LIANG P, OSTERLUND L, CHO BH, OSTER RA, DARNELL B, FRANKLIN F: Alcoholmediated enhancement of postprandial lipemia: a contributing factor to an increase in plasma HDL and a decrease in risk of cardiovascular disease. Am J Clin Nutr 78: 391-399, 2003.

CORRAO G, RUBBIATI L, BAGNARDI V, ZAMBON A, POIKOLAINEN K: Alcohol and coronary heart disease: a meta-analysis. Addiction 95: 1505-1523, 2000.

COSTANZO S, Di CASTELnUOVO A, DONATI MB, IACOVIELlO L, De GAETANO G: Alcohol consumption and mortality in patients with cardiovascular disease: a meta-analysis. J Am Coll Cardiol 55: 1339-1347, 2010.

COSTANZO S, Di CASTELnUOVO A, DONATI MB, IACOVIELlO L, DE GAETANO G: Wine, beer or spirit drinking in relation to fatal and non-fatal cardiovascular events: a meta-analysis. Eur J Epidemiol 26: 833-850, 2011.

CROUSE JR, GERSON CD, DECARLI LM, LIEBER CS: Role of acetate in the reduction of plasma free fatty acids produced by ethanol in man. J Lipid Res 9: 509-512, 1968.

GE H, LI X, WEISZMANN J, WANG P, BARIBAULT H, CHEN JL, TIAN H, LI Y: Activation of G protein-coupled receptor 43 in adipocytes leads to inhibition of lipolysis and suppression of plasma free fatty acids. Endocrinology 149: 4519-4526, 2008.

HOKANSON JE, AUSTIN MA: Plasma triglyceride level is a risk factor for cardiovascular disease independent of high-density lipoprotein cholesterol level: a meta-analysis of population-based prospective studies. J Cardiovasc Risk 3: 213-219, 1996.

HOLMES MV, DALE CE, ZUCCOLO L, SILVERWOOD RJ, GUO Y, YE Z, PRIETO-MERINO D, DEHGHAN A, TROMPET S, WONG A, CAVADINO A, DROGAN D, PADMANABHAN S, LI S, YESUPRIYA A, LEUSINK M, SUNDSTROM J, HUBACEK JA, PIKHART H, SWERDLOW DI, PANAYIOTOU AG, BORINSKAYA SA, FINAN C, SHAH S, KUCHENBAECKER KB, SHAH T, ENGMANN J, FOLKERSEN L, ERIKSSON P, RICCERI F, MELANDER O, SACERDOTE C, GAMBLE DM, RAYAPROLU S, ROSS OA, MCLACHLAN S, VIKHIREVA O, SLUIJS I, SCOTT RA, ADAMKOVA V, ET AL.: Association between alcohol and cardiovascular disease: Mendelian randomisation analysis based on individual participant data. BMJ 349: g4164, 2014.

JORGENSEN AB, FRIKKE-SCHMIDT R, WEST AS, GRANDE P, NORDESTGAARD BG, TYBJAERG-HANSEN A: Genetically elevated non-fasting triglycerides and calculated remnant cholesterol as causal risk factors for myocardial infarction. Eur Heart J 34: 1826-1833, 2013.

KERSTEN S: Physiological regulation of lipoprotein lipase. Biochim Biophys Acta 1841: 919-933, 2014.

KOVAR J, POLEDNE R: The effect of moderate alcohol consumption on lipoprotein metabolism. Cor Vasa 46: 110-114, 2004.

KREBS HA, FREEDLAND RA, HEMS R, STUBBS M: Inhibition of hepatic gluconeogenesis by ethanol. Biochem J 112: $117-124,1969$.

LAWLOR DA, NORDESTGAARD BG, BENN M, ZUCCOLO L, TYBJAERG-HANSEN A, DAVEY SMITH G: Exploring causal associations between alcohol and coronary heart disease risk factors: findings from a Mendelian randomization study in the Copenhagen General Population Study. Eur Heart J 34: 2519-2528, 2013.

MUDRAKOVA E, POLEDNE R, KOVAR J: Postprandial triglyceridemia after single dose of alcohol in healthy young men. Nutr Metab Cardiovasc Dis 23: 183-188, 2013.

NIKKILA EA, TASKINEN MR, HUTTUNEN JK: Effect of acute ethanol load on postheparin plasma lipoprotein lipase and hepatic lipase activities and intravenous fat tolerance. Horm Metab Res 10: 220-223, 1978. 
NISHIWAKI M, ISHIKAWA T, ITO T, SHIGE H, TOMIYASU K, NAKAJIMA K, KONDO K, HASHIMOTO H, SAITOH K, MANABE M, MIYAJIMA E, NAKAMURA H: Effects of alcohol on lipoprotein lipase, hepatic lipase, cholesteryl ester transfer protein, and lecithin:cholesterol acyltransferase in high-density lipoprotein cholesterol elevation. Atherosclerosis 111: 99-109, 1994.

POWNALL HJ: Dietary ethanol is associated with reduced lipolysis of intestinally derived lipoproteins. J Lipid Res 35 : 2105-2113, 1994.

POWNALL HJ, ROSALES C, GILLARD BK, GOTTO AM JR: Alcohol: a nutrient with multiple salutary effects. Nutrients 7: 1992-2000, 2015.

RIMM EB, KLATSKY A, GROBBEE D, STAMPFER MJ: Review of moderate alcohol consumption and reduced risk of coronary heart disease: is the effect due to beer, wine, or spirits. BMJ 312: 731-736, 1996.

RIMM EB, WILLIAMS P, FOSHER K, CRIQUI M, STAMPFER MJ: Moderate alcohol intake and lower risk of coronary heart disease: meta-analysis of effects on lipids and haemostatic factors. BMJ 319: 1523-1528, 1999.

RITSCHELOVÁ I (ed.): Statistical Yearbook of the Czech Republic 2014. Czech Statistical Office, Prague, 2014, p. 424.

RONKSLEY PE, BRIEN SE, TURNER BJ, MUKAMAL KJ, GHALI WA: Association of alcohol consumption with selected cardiovascular disease outcomes: a systematic review and meta-analysis. BMJ 342: d671, 2011.

SARWAR N, SANDHU MS, RICKETTS SL, BUTTERWORTH AS, DI ANGELANTONIO E, BOEKHOLDT SM, OUWEHAND W, WATKINS H, SAMANI NJ, SALEHEEN D, LAWLOR D, REILLY MP, HINGORANI AD, TALMUD PJ, DANESH J: Triglyceride-mediated pathways and coronary disease: collaborative analysis of 101 studies. Lancet 375: 1634-1639, 2010.

SCHNEIDER J, LIESENFELD A, MORDASINI R, SCHUBOTZ R, ZOFEL P, KUBEL F, VANDRE-PLOZZITZKA C, KAFFARNIK H: Lipoprotein fractions, lipoprotein lipase and hepatic triglyceride lipase during short-term and long-term uptake of ethanol in healthy subjects. Atherosclerosis 57: 281-291, 1985.

SCHRIEKS IC, HEIL AL, HENDRIKS HF, MUKAMAL KJ, BEULENS JW: The effect of alcohol consumption on insulin sensitivity and glycemic status: a systematic review and meta-analysis of intervention studies. Diabetes Care 38: 723-732, 2015.

SILER SQ, NEESE RA, CHRISTIANSEN MP, HELLERSTEIN MK: The inhibition of gluconeogenesis following alcohol in humans. Am J Physiol 275: E897-E907, 1998a.

SILER SQ, NEESE RA, PARKS EJ, HELLERSTEIN MK: VLDL-triglyceride production after alcohol ingestion, studied using [2-13C1] glycerol. J Lipid Res 39: 2319-2328, 1998 b.

SILER SQ, NEESE RA, HELLERSTEIN MK: De novo lipogenesis, lipid kinetics, and whole-body lipid balances in humans after acute alcohol consumption. Am J Clin Nutr 70: 928-936, 1999.

TOLSTRUP JS, GRONBAEK M, TYBJAERG-HANSEN A, NORDESTGAARD BG: Alcohol intake, alcohol dehydrogenase genotypes, and liver damage and disease in the Danish general population. Am J Gastroenterol 104: 2182-2188, 2009.

TORRES Do REGO A, KLOP B, BIRNIE E, ELTE JW, RAMOS VC, WALTHER LA, CABEZAS MC: Diurnal triglyceridemia in relation to alcohol intake in men. Nutrients 5: 5114-5126, 2013.

WANG C, XUE H, WANG Q, HAO Y, LI D, GU D, HUANG J: Effect of drinking on all-cause mortality in women compared with men: a meta-analysis. $J$ Womens Health (Larchmt) 23: 373-381, 2014.

WHITFIELD JB, HEATH AC, MADDEN PA, PERGADIA ML, MONTGOMERY GW, MARTIN NG: Metabolic and biochemical effects of low-to-moderate alcohol consumption. Alcohol Clin Exp Res 37: 575-586, 2013.

ZAKHARI S: Overview: how is alcohol metabolized by the body? Alcohol Res Health 29: 245-254, 2006.

ZEMÁNKOVÁ K, MAKOVEICHUK E, VLASÁKOVÁ Z, OLIVECRONA G, KOVÁŘ J: Acute alcohol consumption downregulates lipoprotein lipase activity in vivo. Metabolism 64: 1592-1596, 2015. 